\section{(6) OPEN ACCESS} Professor Michael Parker, The Ethox Centre, Nuffield Department of Population Health, University of Oxford, Old Road Campus, Oxford OX3 7LF, UK; michael.parker@ethox.ox.ac.uk

Received 22 August 2014 Revised 28 September 2014 Accepted 22 October 2014

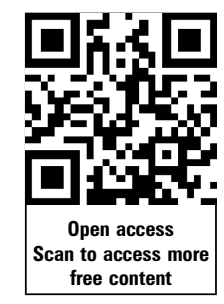

\title{
Scaling ethics up and down: moral craft in clinical genetics and in global health research
}

\author{
Michael Parker
}

\begin{abstract}
This paper engages with the question of what it is to 'do good medical ethics' in two ways. It begins with an exploration of what it might mean to say that health professionals practise good medical ethics as part of practising good ethical medicine. Using the example of the Genethics Club, a well-established national ethics forum for genetics professionals in the UK, the paper develops an account of moral craftsmanship grounded in the concepts of shared moral commitments and practices, moral work, ethics and living morality. In the light of this discussion, the paper goes on to consider what it might mean for a specialist in medical ethics, a bioethicist, to do good medical ethics. Finally, a research agenda focusing on the challenges of thinking about good medical ethics in a global context and a proposal for an innovative approach to bioethics methodology is outlined.
\end{abstract}

In this paper I reflect on the question of what it is to 'do good medical ethics' in two ways. I begin by exploring what it might mean to say that health professionals practise good medical ethics-as part of practising good ethical medicine-using an example from clinical genetics. I then go on, in the light of this discussion, to consider what it might mean for a specialist in medical ethics, a bioethicist, to do good medical ethics. Finally, I outline a research agenda focusing on the challenges of thinking about good medical ethics in a global context.

\section{THE GENETHICS CLUB}

In 2001, Anneke Lucassen, Angus Clarke, Tara Clancy and I established the Genethics Club, a national ethics forum for genetics professionals in the UK. We thought that there might be value and interest in a regular national meeting for the discussion, by practitioners, of practical ethical problems arising in their day-to-day work and for the sharing of good practice. Much to our surprise, the Genethics Club has now been in existence for nearly 14 years. Thirty-eight meetings, with a total attendance of more than 800 people, have taken place. More than 400 cases have been formally presented, and many more discussed. ${ }^{1}$ The fact that there is no funding for the Genethics Club means that those who attend have to arrange and pay for their own transport, contribute towards the cost of the venue hire, and arrange cover for their clinical work. Given this, it is interesting to ask why they continue to attend in such numbers. The answer to this question is unlikely to be simple. However, over time, I have come to understand that an important reason why genetics professionals come to the Genethics Club is their commitment to performing their job as well as possible, both for its own sake and for the patients and families they care for. In what follows, I shall refer to this as a commitment to 'moral craft' (or moral craftsmanship). ${ }^{\text {i } 2}$

\section{MORAL CRAFT ${ }^{\mathrm{ii}}$}

Shared moral commitments and practices

Genetics is sometimes portrayed as a controversial and problematic area of medical practice. But one of the most striking findings of the Genethics Club is that, for genetic counsellors, laboratory staff and medical doctors themselves, such challenges are relatively infrequent and are experienced as contrasting with the majority of their day-to-day practice, which is relatively stable and unproblematic. Patients are seen, histories are taken, screening is offered, treatments are given, and relatives are informed, as genetics professionals come to care for successive generations and different branches of families. Most of the time, genetics professionals do not worry about moral problems or see their practices as deeply problematic. They simply get on with their job.

While it is true that practice in genetics tends not to be characterised on a daily basis by ethical conflict, controversy and ambiguity, or by a constant requirement for reflection, it does always have an important moral dimension. The day-to-day work of genetics professionals involves the making of not only scientific and clinical judgements but also value judgements. Some of these judgements are explicit, such as for example when a genetics professional says that he/she believes that the use of prenatal testing and termination of pregnancy for a minor condition would be inappropriate. In many cases, however, value judgements are implicit in practice in ways that do not have the characteristics of decisions at all. Perhaps the majority of value judgements are like this-built into the genetics professional's day-to-day encounters with patients as settled practices embodying implicit, unspoken values.

\footnotetext{
'Whenever I use the term 'craft' or 'craftsmanship' I worry a lot about the gendered implications of the latter. I prefer the term 'craft' but this misses something important. In addition to the activity to which it pertains, 'craftsmanship' also brings to mind certain relevant virtues, attitudes and commitments.

${ }^{\mathrm{ii}}$ This section draws upon the argument I make in chapter six of my book, Ethical Problems and Genetics Practice. ${ }^{1}$
} 
None of this should be taken as suggesting that the working life of the genetics professional is, or is experienced as, easy. To say that much of the day-to-day work of the genetics professional is relatively stable and underpinned by a heritage of tacit knowledge and shared approaches to good practice does not mean that they do not have to make difficult value judgements in their work with patients and families. Clearly they do. Even broadly shared and stable commitments require interpretation and judgement in particular cases. And even though these judgements will be informed by experience and by the 'rules of thumb' that together make up 'good practice', every case presents its own unique challenges.

\section{Moral work}

Shared practice is only ever relatively stable, and shared commitments are always to some degree provisional. Sometimes, perhaps not infrequently, genetics professionals encounter situations in which there are tensions between the requirements of different moral commitments or between rules of thumb, which call for conflicting courses of action. A relatively common example of this is where there are tensions between the important and largely shared moral commitments of genetics professionals to the care of the patient and the care of the family-perhaps because a patient refuses to share clinically useful information with family members. Here, the genetics professional's commitment to caring for the individual patient and to respecting patient confidentiality is in practical tension with a commitment to ensuring that family members who are at risk of an inherited condition and who might benefit from genetic testing, screening and treatment receive information, support and advice. In this kind of situation, the successful management of the tension between two commitments in order to find a solution that respects both requires 'moral work'. Experienced health professionals tend to be extremely good at this. They will counsel the patient, supporting him or her and offering advice, and, while remaining steadfastly patient-centred and respecting the requirements of the law and guidelines on confidentiality, encourage him or her to see the importance of the sharing of information and suggest ways in which this might be possible, offering practical help and support with this where necessary. This is how genetics professionals make it possible for patients to share information with family members despite their anxiety or initial reluctance to do so. This is also how the genetics professional carries out the work required to make it possible to meet his/her obligations to both the patient and their family. If much everyday practice in genetics is relatively stable and unproblematic, this is largely because of the moral work of genetics professionals through which the implications of these commitments and of models of 'good practice' are worked out.

\section{Ethics}

As this example suggests, the moral work of genetics professional is usually successful in meeting moral commitments and sustaining good practice. However, what the cases presented by genetics professions at the Genethics Club illustrate-and the very fact that they bring such cases for discussion-is that there are some situations in which the commitments and views about good practice held by genetics professionals are brought into question and become objects of concern and deliberation. What this highlights is the fact that, against a broad background of broadly shared views about good practice and more or less effective moral work, there are nevertheless some cases experienced by genetics professionals that call for a rather different kind of work-work I call 'ethics'. These are situations in which the rules of thumb and implicit and explicit commitments and value judgements that sustain and make moral work possible no longer provide convincing solutions to the problems encountered and are indeed seen to generate more problems-or perhaps problems of different kinds. These are not merely situations requiring genetics professionals to pause and think carefully about what they are doing or to work with patients and colleagues to find ways of working out practical solutions that are compatible with existing-if sometimes conflicting-practices and values. These kinds of situations are sometimes called 'ethical dilemmas' by health professionals and are seen as very significant by those who attend the Genethics Club-and indeed by anyone who takes the idea of good practice and craftsmanship seriously-because they call into question what counts as good practice. Such cases are very familiar to those with an interest in bioethics and have been the subject of much valuable and interesting discussion in the Journal of Medical Ethics over the past 40 years.

\section{Living morality}

As it stands, this account of the relationship between moral practices and ethics misses something important about moral craftsmanship. Not all of what is ethically important can be explained in terms of the emergence of shared commitments and rules of thumb as ethical problems against a broad background of otherwise shared commitments. There are two main reasons for this. The first is that the problems that arise in the day-to-day work of genetics professionals are inevitably to some degree contingent on the kinds of patients and families they see and the things that happen in their working day. Even if it is often the case that such problems resonate with the experiences of others elsewhere and are agreed to be important, to view such problems as the limit of ethics would be to give a much too prominent role to moral luck. Another reason for being wary of a problem-based approach to ethics is that medicine is full of examples of practices that were at one time widely agreed to be good practice but have subsequently come to be seen as highly problematic. This serves as a useful reminder that what seems to be good practice today may look very different in the future. It is not the mere possibility of change that is the concern here; this is not a worry about relativism. The worry is that the mere fact that there is or is not disagreement about a particular practice does not in itself provide an answer to the question of whether the practice is right or good or morally praiseworthy. The practices that are often most in need of critical reflection are those that are widely seen as unproblematic.

What this means for moral craftsmanship and good medical ethics is that skilled genetics professionals must be able to inhabit the relatively stable, shared and unproblematic moral traditions underpinning everyday good practice and must also be skilled at identifying areas of practice that should be subjected to critical reflection. This itself presents a practical moral problem that is not often discussed. When and in what kinds of situations should health professionals continue to apply the relatively stable, unproblematic traditions and rules of thumb that together constitute 'good practice', and when and in what kinds of contexts should they view such practices as objects of ethical concern and subject them to critical reflection and deliberation? Not everything can be an ethical problem at the same time, partly because this would undermine good practice and partly because the concept of a moral problem only makes sense in the context of largely shared agreements in practice and in moral judgements. This question about when to inhabit established practices and when to subject them to critique is one to which 
there can be no simple answer or unambiguous rule of thumb by which judgement might be guided. This is not surprising. There is no reason why ethical problems and the need for ethical reflection should always emerge in the same way. This is likely to be highly contextual and its resolution dependent on the embedded practical wisdom of the experienced health professional.

Given this, the experienced genetics professional committed to the moral craft of genetics is going to place particular value on the continuation of an active and productive interplay between shared moral commitments and assumptions on the one hand and critical ethical reflection on the other as a technique for ensuring that his/her practice is characterised by what might perhaps be thought of as a 'living morality' - a mode of engagement with practice that makes it possible for both ethics and morals to be taken seriously. ${ }^{3}$ The genetics professional skilled in moral craft recognises that, while the commitments underpinning everyday good practice will sometimes emerge as ethical objects of concern in their own way and in their own time-prompted perhaps by the inherent instability of practice, because practice is always rather tentative or because moral work is only ever partially successful in particular cases- the sustainability and indeed the vitality of the living morality at the heart of moral craftsmanship depends on the genetics professional's own commitment to the moral work of 'problem-seeking'.

This starts to suggest an answer to the question with which this paper began: Why is it that the Genethics Club has been so popular with genetics professionals? I suggested above that the genetics professionals who attend the Genethics Club share a deep commitment to carrying out their job well for its own sake and recognise that this requires a commitment not only to good practice in the medical aspects of their day-to-day practice but also in what I have referred to as the 'moral craft' of genetics. Against this background commitment to moral craftsmanship, the discussion in this paper has begun to suggest that, while genetics professionals might initially attend because they are looking for solutions, the reason they stay is because of a growing recognition of the importance of 'problems' in the development and practice of moral craftsmanship. For genetics professionals who are committed to good practice, the Genethics Club has become valuable as a space not only for the reaching of solutions to particular ethical problems but also as a way of keeping their practice open and of working to maintain a sustainable living morality. The Genethics Club is not only a place of discussion and deliberation but is also a technique for the unsettling of everyday, established stable practices in productive ways, which facilitate moral craftsmanship and the emergence of the practical wisdom at the heart of good medical ethics practice.

\section{The role of the bioethicist}

This account of the role of moral craftsmanship in clinical genetics is both descriptive and normative. That is, it is an account of both the practice of a particular group of genetics professionals strongly committed to thinking about the ethical aspects of their work and of what medical practice ought to be like. This has implications for both medical ethics education and the role of the bioethicist. It suggests, among other things, that one important role of the bioethicist-both in clinical ethics work and in research and publication-is to promote and support the development of moral craftsmanship and the practical wisdom essential to good practice. The requirements will vary. In some cases, where health professionals or reflective medical researchers are already committed to the development and exercise of moral craftsmanship, such as those who attend the Genethics Club, the role of the bioethicist may be to support them in this-to provide opportunities to critically reflect on their practice, hear about the experiences of others, talk through disagreements, explore shared solutions, etc. In other cases, perhaps with health professionals or policy makers who are less strongly committed to moral craftsmanship or who perhaps are insufficiently critically reflective of the value assumptions underpinning their practice, the role of the ethicist will need to be more disruptive-or perhaps more entertaining - to promote such awareness or reflection.

Whichever of these pertains, in order to be effective, bioethicists should be concerned to engage with the ethical issues faced by real world actors in real world settings and should seek to engage with and enter into the moral worlds of health professionals, medical researchers, patients and policy-makers.

\section{TESTING THE LIMITS OF MORAL CRAFT}

A number of criticisms of the concept of moral craftsmanship are possible. Given the limits of space, I want to briefly discuss only two of these here: one of 'nostalgia' and another of 'parochialism'.

To consider nostalgia first-one possible criticism of the idea of moral craftsmanship is that it is at best idealistic and at worst nostalgic. It is nostalgic in the sense that it harks back to a time when the values of medical practice were more widely shared between health professionals and between patients and health professionals. If moral craftsmanship in medicine existed at all, it is a thing of the past. The criticism from nostalgia is that these conditions no longer pertain-that there is an ever-increasing diversity of values, both within the professions and between publics, and much less unquestioned acceptance of professional knowledge, values and practices than there used to be. Notwithstanding the complexities and diversity of contemporary medical practices, public and lives, my research in the Genethics Club and my time spent in genetics clinics over a period of more than 15 years suggests that the critique from nostalgia is misplaced. While there is not the space here to provide extended illustrative examples, my empirical ethics research suggests that, even in the 21 st century genetics clinica place where differing views might be expected-practice is informed by a significant range of shared values, concerns, practices and commitments-and ethical problems. ${ }^{1}$

The second critique, that of parochialism, is that the concept of moral craftsmanship as an account of ethics and morals is too local and has no explanatory or analytical power when thinking about ethics in situations that do not have this local, communal form. If this were true, it would be an important weakness because much that is of contemporary interest in bioethics takes the form of complex, globally distributed, large-scale and technologically innovative activities. If an account of bioethics were incapable of engaging with these activities and problems as well as those of the clinic-that is, if it was incapable of scaling up and down-this would be a reason to reject it. An approach to bioethics that would be capable of making a contribution across the field would need to be capable of scaling up and down. This critique is independent of the first because, even if it were true that genetics professionals in the UK, who might perhaps be seen as a relatively close-knit professional group, exhibit moral craftsmanship founded in shared practices and commitments and a shared commitment to the development of moral craftsmanship, this might nevertheless not be the case in much more geographically distributed forms of medical practice 
and medical research. The concept of moral craftsmanship might be parochial even if it is not nostalgic.

The critique of parochialism has intuitive force, and for that reason is worth interrogating further. My current research, with partners across the Global Health Bioethics Network, in Kenya, Thailand, Malawi, Vietnam and South Africa, seeks to accomplish this through a multidisciplinary exploration and analysis of the moral worlds of research actors in collaborative global health networks. ${ }^{4}$ We are conducting a range of empirical ethics research projects in each of these settings-and in some cases across several-on key practical ethical problems arising for diverse and geographically distributed research actors in global health research collaborations. These include, but are not limited to, questions relating to: data-sharing; consent; benefits and payments; the responsibilities of researchers to communities; research with children; research in epidemics; and standards of care. In parallel with this, I am also exploring the moral world of the global health scientists involved in international research collaborations through observations and interviews with research actors playing different roles in different but connected places. While it is early days, my sense is that the concepts of shared moral practices, moral work, ethics and living morality introduced above may indeed have the potential to perform useful and productive analytical work in the context of global health research as well as in the genetics clinic. This suggests, against the critique of parochialism, that speaking meaningfully and interestingly about ethics in terms of shared practices, commitments and indeed problems may not (necessarily) need to be limited to discussion of small, relatively homogeneous or relatively local contexts. Indeed, it also suggests that scaling up and scaling down may be a potentially interesting and productive methodological approach to thinking about and doing good medical ethics.

Funding The Global Health Bioethics Network is supported by a Wellcome Trust Strategic Award (096527).

Competing interests None.

Provenance and peer review Commissioned; internally peer reviewed.

Open Access This is an Open Access article distributed in accordance with the Creative Commons Attribution Non Commercial (CC BY-NC 4.0) license, which permits others to distribute, remix, adapt, build upon this work non-commercially, and license their derivative works on different terms, provided the original work is properly cited and the use is non-commercial. See: http://creativecommons.org/ licenses/by-nc/4.0/

\section{REFERENCES}

1 Parker M. Ethical problems and genetics practice. Cambridge: Cambridge University Press, 2012.

2 Sennett R. The Craftsman. London: Penguin Books, 2009.

3 Glover J. Causing death and saving lives. London: Penguin Books, 1977:26-9.

4 The Global Health Bioethics Network. http://e-mops.ning.com (accessed 28 Nov 14). 